\title{
Seropositivity for CMV, EBV, HBV, HCV, and HIV in Leukemia Patients and Its Relationship with Cytogenetic Changes
}

Mohammad Eslami

AJA University of Medical Sciences

Vahid Falahati

Medical student at school of medicine, Arak university of medical sciences

Soheila siroosbakht

AJA University of Medical Sciences

Mahdi Nikoohemmat

Medical student at school of medicine, Arak university of medical sciences

Nahid Arabi ( $\nabla$ n.aarabi@ajaums.ac.ir)

AJA University of Medical Sciences

\section{Research Article}

Keywords: Chromosomal Abnormalities, Leukemia, Viral Diseases

Posted Date: January 11th, 2022

DOI: https://doi.org/10.21203/rs.3.rs-1235219/v1

License: (9) This work is licensed under a Creative Commons Attribution 4.0 International License. Read Full License 


\section{Abstract}

Introduction: Leukemias are involving the bone marrow and the soft tissues in inner parts of the bones, where new blood cells are formed. This malignancy is the most common pediatric cancer, which its etiologic causes are not well understood. This multifactorial disease is believed to linked with genetic and non-hereditary environmental factors. Cytogenic analyses of chromosomal abnormalities provide diagnostic and prognostic values in leukemia patients. Given the high prevalence of viral diseases and clinical suspicions on the relationship between certain viral infections and leukemia, it is necessary to investigate this possible relationship, especially in third-world countries. The present study recruited 65 children with leukemia (AML, CML, or ALL) who were presented to two tertiary hospitals. At first, all the patients underwent testing for HBV, HCV, CMV, EBV, and HIV. Bone marrow specimens were studied for identifying possible chromosomal abnormalities in cytogenic investigations. According to our findings, there was a relationship between incidence of leukemia, the 12:21 chromosomal translocation and CMV infection. Therefore, preventing CMV infection can lead to a reduced incidence of leukemia. It is expected that the findings of this study enlighten the scientists to conduct more extensive research on the relationship between viral diseases and leukemia in third-world countries.

Method:The present study recruited 65 children with leukemia (AML, CML, or ALL) who were presented to two tertiary hospitals. At first, all the patients underwent testing forHBV, HCV, CMV, EBV, and HIV. Bone marrow specimens were studied for identifying possible chromosomal abnormalities in cytogenic investigations.

Result:According to our findings,there was a relationship between the incidence of leukemia,the 12:21 chromosomal translocation, and CMV infection. Therefore, preventing CMV infection can lead to a reducedincidence of leukemia.

Conclusion:In this study, we demonstrated that leukemia is relevant to the 12:21 chromosomal translocation and CMV virus infections, So the reduction in leukemia prevalence is dependent on the prevention of CMV disease. It is expected that the findings ofthis studyenlighten the scientists to conduct more extensive researchon the relationship between viral diseasesand leukemia in third-world countries.

\section{Trial registrations:}

Clinical trial registration code:IR.AJAUMS.REC.1399.161

Evaluated by: AJA UNIVERSITY OF MEDICAL SCIENCES

Approval Date:2020-11-15

Approval statement: The project was found to be in accordance with the ethical principles and the national norms and standards for conducting Medical Research in Iran.

\section{Introduction}


Leukemia, a common hematologic malignancy in children, usually originatesfrom the bone marrow andcausesabnormal cell proliferation in the peripheral blood (1). This malignancyis classified intodifferentcategories based on the cell lines involved, including Chronic Lymphocytic Leukemia (CLL), Acute Lymphoblastic Leukemia (ALL), Chronic Myeloid Leukemia (CML), and Acute Myeloid Leukemia (AML). All leukemiasresult from an uncontrolledproliferationof myeloid and lymphocytic precursor cellsand theiraccumulation in the bone marrow. There are multiple forms ofleukemia occurring in children, ALL is the most common form of childhood leukemia followed by $\operatorname{AML}(2,3)$.Leukemia cells also influencethe proliferation of other blood cells in the bone marrow, including the erythrocytes and platelets (4). Treatment of Leukemia is complicated and depends on the patients' age andtheir health status, as well as the type of leukemia and the extent of the disease $(5,6)$. Some common presentations of leukemia include fever, chills, fatigue, weakness, anorexia, nausea, weight loss, night sweats, bone,and joint pain, dyspnea, recurrent infections, and cutaneouslesions. Respiratory tract infections and pneumonia are the leading causes of death in these patients (7).

The etiology of leukemia has not yetbeen fully understood, and a combination of genetic and nonhereditary, environmental factors forms the major risk factors. People withsmoking, exposure to ionizing radiation and chemicals like benzene, previous chemotherapy, and Down syndrome are predisposed to the disease(8). Moreover, individuals with a family history of leukemia have a higher risk of developingthe disease (9). The therapeutic measures for this disease include chemotherapy, radiotherapy, targeted therapies, bone marrow transplantation, or a combination of these methods. Supportive and palliative care can be also provided $(10,11)$.

Similar to other cancers, leukemia is caused by DNA mutations, which activateoncogene, inhibittumor suppressor genes, and cause malfunctioning in the normal cell cycle, cell maturation, and apoptosis (12). In addition to genemutations, some chromosomal abnormalities can also pose an increased risk of leukemia development. For example, Down and Fanconi syndromes are risk factors for AML development(13). In general, structural and numerical abnormalities of the chromosomes can be predisposing factors for leukemia and impact the response to treatment. Therefore, several studies have emphasized the application of cytogenetic analyses of chromosomal abnormalities in diagnosing leukemia, determining its prognosis, andselecting appropriate treatmentsfordisease management (1416). It is now estimated that $10 \%$ of the world's cancers are attributed to viral infections, with the vast majority (> 85\%) occurring in developing countries (17).

Considering the high prevalence of viral infections andthe clinical suspicions on the possible relationship between viral infections and leukemia, the importance of performing independent studies thatinvestigate thepotentialrelationshipbetween these viral infectionsand thecytogeneticabnormalities in leukemia patients is highlighted. Therefore, the present study investigated this relationship

\section{Methods}

Participant Characteristics 
This cross-sectional descriptive study recruited 65 patients with leukemia (AML, CML, or ALL) who were presented to the Amirkabir Hospital, Arak, Iran, and the Golestan Hospital, Tehran, Iran, between November 2020 and August 2021. The participants were included in the study after giving written informed consent. The bone marrow and blood samples used in the present study were primarily provided for conventional diagnostic and therapeutic purposes, and the participants did not undergo any diagnostic test and sampling merely due to the study.

Demographic features and medical history information, including the current age, age of disease onset, family history, and medical history were initially collected.

\section{Viral infection investigations}

To diagnose HBV, HCV, CMV, EBV, and HIV, the participants were referred to the laboratories of the Amirkabir Hospital, Arak, Iran,or the Golestan Hospital, Tehran, Iran.An Enzyme-Linked Immunosorbent Assay (ELISA) technique was used for the diagnosis.

\section{Chromosomal abnormality investigations}

A volume of $3 \mathrm{~mL}$ of bone marrow was aspirated from the participants. Then, the bone marrow aspirates

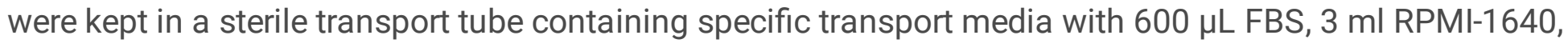
and $100 \mu \mathrm{l}$ sodium heparin. At the same or next day, 200-800 $\mu$ l of each bone marrow specimen was cultured in a media containing $20 \% \mathrm{FBS}, 5 \mathrm{ml}$ Marrowmax medium, $100 \mathrm{U} / \mathrm{ml}$ penicillin or streptomycin, and $2 \mathrm{mM} \mathrm{L-glutamine.} \mathrm{The} \mathrm{samples} \mathrm{were} \mathrm{incubated} \mathrm{for} 24$ hours at a temperature of $37^{\circ} \mathrm{C}$. Then, 50 $\mu$ calcined $(10 \mu \mathrm{g} / \mathrm{ml})$ was added, followed by 20 minutes of incubation. In the following, 7-8 $\mathrm{ml}$ hypotonic solutionof potassium chloride was added. After 25 minutes, a fixative solution containing methanol and acetic acid (ratio: $3: 1$ ) was added to the smears of each specimen thrice. In the next step, slides were prepared from the chromosomes at metaphase in an environment with controlled humidity and temperature. The slides were incubated for 24 hours at a temperature of $65^{\circ} \mathrm{C}$ and then stained using the trypsin-Giemsa technique (19).

\section{Statistical analysis}

Data analysis was performed using descriptive and analytical statistical methods. The SPSS version 22 (IBM (c) Corp., Armonk, NY, USA) was used, and the results obtained were reported in absolute frequency and percentage (\%). Moreover, the table and diagrams summarized the results. Finally, analyses were made to assess the frequency and the type of chromosomal abnormalities in patients seropositive for $H B V, H C V, C M V$, EBV, and HIV.

\section{Results}

We evaluated 65 patients which $69.20 \%$ of them $(n=45)$ were boys. The mean age was $6.56 \pm 2.11$ and $69.23 \%$ of participates $(n=45)$ were in $1-7$ age groups. Also, $26.15 \%(n=17)$ and $4.62 \%(n=3)$ were in $8-15$ and more than 15 years age groups respectively. 
Table 1 shows the distribution of chromosomal abnormalities in the participants. Based on this table, the most of chromosomal abnormalities were related to chromosomal translocation (12:21) $(n=30,46.2 \%)$. While, inversion 16 and translocations of $t(8: 16), t(8: 21)$, and $t(8: 14)$ were shown in a few cases.

None of the children were infected with HIV, HBV, and HCV. Hence, no significant relationship was found between these infections and chromosomal abnormalities in leukemia patients. Moreover, two patients were infected with EBV and four patients were infected with CMV which all of them had chromosomal translocation (12:21). However, according to Table 2, further analyses showed no significant relationship between $\mathrm{HBs} \mathrm{Ab}$ and chromosomal abnormalities $(P>0.05)$.

\begin{tabular}{|llll|}
\hline \multicolumn{4}{|l}{ Table 1. Distribution of chromosomal abnormalities in the study participants } \\
\hline Chromosomal abnormality & $\begin{array}{l}\text { Frequency } \\
(\mathrm{n}=65)\end{array}$ & $\begin{array}{l}\text { Percentage } \\
(\%)\end{array}$ & $95 \% \mathrm{Cl}$ \\
\hline Chromosomal translocation & & & \\
\hline$(12: 21)$ & 30 & 46.2 & $36.57-63.42$ \\
\hline$(8: 16)$ & 1 & 1.5 & $0.04-9.23$ \\
\hline$(15: 17)$ & 4 & 6.2 & $7.34-27.42$ \\
\hline$(9: 22)$ & 4 & 6.2 & $7.34-27.42$ \\
\hline$(8: 21)$ & 1 & 1.5 & $0.04-9.23$ \\
\hline$(8: 14)$ & 1 & 1.5 & $0.04-9.23$ \\
\hline Down mosaicism & 1 & 1.5 & $0.04-9.23$ \\
\hline Trisomy 21 & 3 & 4.6 & $0.4-11.90$ \\
\hline Inversion 16 & 1 & 1.5 & $0.04-9.23$ \\
\hline Without translocation/ undetermined translocation & 19 & 29.2 & $18.57-63.42$ \\
\hline
\end{tabular}




\begin{tabular}{|llll|}
\hline \multicolumn{3}{|l}{ Table 2. The relationship between HBs Ab and chromosomal abnormalities in the study participants } \\
\hline Chromosomal abnormality & Negative & Positive & P-value \\
& $\mathrm{N}=17$ & $\mathrm{~N}=48$ & \\
$\mathrm{t}(12: 21)$ & $8(47.05)$ & $22(45.83)$ & 0.919 \\
\hline $\mathrm{t}(8: 16)$ & $1(5.88)$ & $0(0.0)$ & \\
\hline $\mathrm{t}(15: 17)$ & $0(0.0)$ & $4(8.33)$ \\
\hline $\mathrm{t}(9: 22)$ & $2(11.76)$ & $2(4.16)$ \\
\hline $\mathrm{t}(8: 21)$ & $1(5.88)$ & $0(0.0)$ \\
\hline $\mathrm{t}(8: 14)$ & $0(0.0)$ & $1(2.08)$ \\
\hline Down mosaicism & $0(0.0)$ & $1(2.08)$ \\
\hline Trisomy 21 & $0(0.0)$ & $3(6.25)$ \\
\hline Inversion 16 & $1(5.88)$ & $0(0.0)$ \\
\hline Without translocation/ undetermined translocation & $4(23.52)$ & $15(31.25)$ \\
\hline * P-value was calculated by chi-2 statistics at 95\% levels of Cl & & \\
\hline
\end{tabular}

Table 3 evaluated the association between leukemia types with viral infections, including HIV, EBV, CMV, $\mathrm{HBV}$, and HCV. There were no significant differences between frequencies of these infections based on types of leukemia. 


\begin{tabular}{|c|c|c|c|}
\hline \multirow[t]{2}{*}{ Viral Infection } & \multicolumn{2}{|c|}{ Type of Leukemia } & \multirow[t]{2}{*}{ P-value* } \\
\hline & ALL $(n=59)$ & $\operatorname{AML}(n=6)$ & \\
\hline \multicolumn{4}{|l|}{ HIV } \\
\hline Negative & $59(100.0)$ & $6(100.0)$ & \multirow[t]{2}{*}{-} \\
\hline Positive & $0(0.0)$ & $0(0.0)$ & \\
\hline \multicolumn{4}{|l|}{ HBV } \\
\hline Negative & $57(96.61)$ & $6(100.0)$ & \multirow[t]{2}{*}{0.647} \\
\hline Positive & 2 (3.39) & $0(0.0)$ & \\
\hline \multicolumn{4}{|l|}{ CMV } \\
\hline Negative & $55(93.22)$ & $6(100.0)$ & \multirow[t]{2}{*}{0.510} \\
\hline Positive & $4(6.78)$ & $0(0.0)$ & \\
\hline \multicolumn{4}{|l|}{ HCV } \\
\hline Negative & $59(100.0)$ & $6(100.0)$ & \multirow[t]{2}{*}{-} \\
\hline Positive & $0(0.0)$ & $0(0.0)$ & \\
\hline \multicolumn{4}{|l|}{$\mathrm{HBs} \mathrm{Ab}$} \\
\hline Negative & $15(25.42)$ & 2 (33.33) & \multirow[t]{2}{*}{0.674} \\
\hline Positive & $44(74.58)$ & $4(66.67)$ & \\
\hline \multicolumn{4}{|l|}{$\mathrm{HBs} \mathrm{Ag}$} \\
\hline Negative & $59(100.0)$ & $6(100.0)$ & \multirow[t]{2}{*}{-} \\
\hline Positive & $0(0.0)$ & $0(0.0)$ & \\
\hline
\end{tabular}

\section{Discussion}

Cancer with 6.7 million deaths per year, is a devastating disease that causes serious problems for the affected people, their families, and health care systems (18). The development of treatment and prevention strategies for the management of cancer depends on our knowledge of cancer cells and the caused mechanisms. Over the past 30 years, it has become clear that several viruses play an important 
role in the multistage development of human neoplasms $(19,20)$. Oncogenic viruses can contribute to various stages of the carcinogenic process. The association of the virus with particular cancer can be between $15-100 \%$ (20). In addition to elucidating the cause of many human cancers, the study of carcinogenic viruses has been invaluable in discovering and analyzing key cell pathways in cancer.

The present study investigated the relationship between chromosomal abnormalities in children with leukemia and with viral infections of CMV, EBV, HCV, HBV, and HIV. This study aimed to establish a better understanding of the possible relationships between leukemias and certain viral infections and thus enlightens the public healthcare system in developing countries to save people at risk of leukemia by controlling the incidence of viral diseases.

In this study, 65 children with leukemia were studied to investigate the association between viral diseases and the possibility of genetic abnormalities. Among 65 patients, $69.20 \%$ were boys and $30.80 \%$ were girls. Also, most of the children participating in the study (69.23\%) were between 1-7 years old. The mean age of the children was $6.84 \pm 4.40$ years. The frequency of leukemia in children was found $92.3 \%$ with ALL. Also, the frequency of chromosomal displacement in children showed that most of them, $46.2 \%$, had a 12:21 chromosomal shift in their genome.

According to our results, no significant relationship was found between chromosomal abnormalities and viral infections with HIV, EBV, HBV, and HCV $(P>0.05)$. Therefore, it can be concluded that none of these viral infections can lead to chromosomal abnormalities, and thus increase the risk of leukemia. On the other hand, our results on the prevalence of positive CMV IgG in the study participants showed that four children infected with CMV had chromosomal translocation (12:21) in their genomes. Thus, CMV infection is highly suspected to cause a chromosomal abnormality and predispose children to leukemia $(\mathrm{P}<0.5)$.

The main objective of the present study was to investigate the relationship between lifelong exposure to $\mathrm{HBV}, \mathrm{HCV}, \mathrm{HIV}, \mathrm{EBV}$, and CMV and the possibility of gene mutations or chromosomal translocations leading to leukemia. In general, it is the CMV infection that requires greater attention compared to other viral infections. Therefore, preventive measures aiming to reducethe incidence of leukemia should be focused on controlling the cytomegalovirus infection, especially in third-world countries where viral diseases are prevalent.

\section{Declarations}

I confirm that I understand the European Journal of Medical Research is an open-access journal that levies an article-processing charge per article accepted for publication. By submitting my article I agree to pay this charge in full if my article is accepted for publication.

No, I declare that the authors have no competing interests as defined by BMC, or other interests that might be perceived to influence the results and/or discussion reported in this paper. 
The results/data/figures in this manuscript have not been published elsewhere, nor are they under consideration (from you or one of your Contributing Authors) by another publisher.

I have read the BMC journal policies on author responsibilities and submitted this manuscript under those policies.

All of the material is owned by the authors and/or no permissions are required.

I am the author responsible for the submission of this article and I accept the conditions of submission and the BMC Copyright and License Agreement as detailed above.

Conflict of interest: The authors state that there is no contradiction of interests in the current study.

Data Availability

All relevant data are within the manuscript and its Supporting Information files.

Conflict of interest: The authors state that there is no contradiction or conflict of interest in the current study.

Funding: This work is funded and supported by AJA University of Medical Sciences, Iran.

Author's contributions: The authors, M.E, V.A, M.N, S.S, and N.A, have all contributed to the research and data analysis of the paper. M.E has written all of the parts.

Acknowledgments: We wish to thank the esteemed officials of the Army University of the Islamic Republic of Iran and all the dignitaries who contributed to the implementation of this project for their financial and moral support.

\section{References}

1. Beatty CF. Community Oral Health Practice for the Dental Hygienist-E-Book: Elsevier Health Sciences; 2016.

2. Döhner H, Weisdorf DJ, Bloomfield CD. Acute myeloid leukemia. New England Journal of Medicine. 2015;373(12):1136-52.

3. Appelbaum FR, Gundacker H, Head DR, Slovak ML, Willman CL, Godwin JE, et al. Age, and acute myeloid leukemia. Blood. 2006;107(9):3481-5.

4. Elliot P, Wakefield JC, Best NG, Briggs DJ. Spatial epidemiology: methods and applications: Oxford University Press; 2000.

5. Short NJ, Konopleva M, Kadia TM, Borthakur G, Ravandi F, DiNardo CD, et al. Advances in the treatment of acute myeloid leukemia: new drugs and new challenges. Cancer discovery. 2020;10(4):506-25. 
6. Samra B, Jabbour E, Ravandi F, Kantarjian H, Short NJ. Evolving therapy of adult acute lymphoblastic leukemia: state-of-the-art treatment and future directions. Journal of hematology \& oncology. 2020;13:1-17.

7. Landgren O, Rapkin JS, Caporaso NE, Mellemkjaer L, Gridley G, Goldin LR, et al. Respiratory tract infections and subsequent risk of chronic lymphocytic leukemia. Blood. 2007;109(5):2198-201.

8. Tang L, Wu J, Li C-G, Jiang H-W, Xu M, Du M, et al. Characterization of immune dysfunction and identification of prognostic immune-related risk factors in acute myeloid leukemia. Clinical cancer research. 2020;26(7):1763-72.

9. van der Plas E, Noakes TLS, Butcher DT, Weksberg R, Galin-Corini L, Wanstall EA, et al. Cognitive and behavioral risk factors for low quality of life in survivors of childhood acute lymphoblastic leukemia. Pediatric Research. 2020:1-8.

10. Burnett A, Wetzler M, Lowenberg B. Therapeutic advances in acute myeloid leukemia. J Clin Oncol. 2011;29(5):487-94.

11. Florean C, Schnekenburger M, Grandjenette C, Dicato M, Diederich M. Epigenomics of leukemia: from mechanisms to therapeutic applications. Epigenomics. 2011;3(5):581-609.

12. Radivoyevitch T, Sachs R, Gale R, Molenaar R, Brenner D, Hill B, et al. Defining AML and MDS second cancer risk dynamics after diagnoses of first cancers treated or not with radiation. Leukemia. 2016;30(2):285-94.

13. Saida S. Predispositions to leukemia in down syndrome and other hereditary disorders. Current treatment options in oncology. 2017;18(7):1-13.

14. Mrózek K, Heinonen K, Bloomfield CD. Clinical importance of cytogenetics in acute myeloid leukaemia. Best Practice \& Research Clinical Haematology. 2001;14(1):19-47.

15. Haferlach T, Schmidts I. The power and potential of integrated diagnostics in acute myeloid leukaemia. British journal of haematology. 2020;188(1):36-48.

16. Zhou YL, Wu LX, Peter Gale R, Wang ZL, Li JL, Jiang H, et al. Mutation topography and risk stratification for de novo acute myeloid leukaemia with normal cytogenetics and no nucleophosmin 1 (NPM1) mutation or Fms-like tyrosine kinase 3 internal tandem duplication (FLT3-ITD). British journal of haematology. 2020;190(2):274-83.

17. Schiller JT, Lowy DR. Virus infection and human cancer: an overview. Viruses and human cancer. 2014:1-10.

18. Sung H, Ferlay J, Siegel RL, Laversanne M, Soerjomataram I, Jemal A, et al. Global cancer statistics 2020: GLOBOCAN estimates of incidence and mortality worldwide for 36 cancers in 185 countries. CA: a cancer journal for clinicians. 2021;71(3):209-49.

19. Hausen Hz. Viruses in human cancers. Current Science. 2001:523-7.

20. Parkin DM. The global health burden of infection-associated cancers in the year 2002. International journal of cancer. 2006;118(12):3030-44. 